Article

\title{
Adverse Impact of DNA Methylation Regulatory Gene Mutations on the Prognosis of AML Patients in the 2017 ELN Favorable Risk Group, Particularly Those Defined by NPM1 Mutation
}

\author{
James $\mathrm{Yu}{ }^{1,+} \mathbb{D}$, Jingxin Sun ${ }^{2,+}$, Yuan $\mathrm{Du}^{3}$, Rushang Patel ${ }^{4}$, Juan Carlos Varela ${ }^{4}$, Shahram Mori ${ }^{4}$ and \\ Chung-Che Chang ${ }^{5,6, *}$
}

check for

updates

Citation: Yu, J.; Sun, J.; Du, Y.; Patel, R.; Varela, J.C.; Mori, S.; Chang, C.-C. Adverse Impact of DNA Methylation Regulatory Gene Mutations on the Prognosis of AML Patients in the 2017 ELN Favorable Risk Group,

Particularly Those Defined by NPM1 Mutation. Diagnostics 2021, 11, 986. https://doi.org/10.3390/diagnostics 11060986

Academic Editor:

Irena Misiewicz-Krzeminska

Received: 24 April 2021

Accepted: 28 May 2021

Published: 29 May 2021

Publisher's Note: MDPI stays neutral with regard to jurisdictional claims in published maps and institutional affiliations.

Copyright: (c) 2021 by the authors Licensee MDPI, Basel, Switzerland. This article is an open access article distributed under the terms and conditions of the Creative Commons Attribution (CC BY) license (https:/ / creativecommons.org/licenses/by/ $4.0 /)$.
1 Department of Internal Medicine, AdventHealth Orlando, Orlando, FL 32804, USA; James.Yu.MD@AdventHealth.com

2 Department of Hematology and Medical Oncology, Baylor College of Medicine, Houston, TX 77030, USA; Jingxin.Sun@bcm.edu

3 Research Institute, AdventHealth Orlando Hospital, Orlando, FL 32804, USA; Yuan.Du@AdventHealth.com

4 Blood and Marrow Transplant Center, AdventHealth Orlando Hospital, Orlando, FL 32804, USA; Rushang.Patel.MD@AdventHealth.com (R.P.); Juan.Varela.MD@AdventHealth.com (J.C.V.); Shahram.Mori.MD@AdventHealth.com (S.M.)

5 Department of Pathology and Laboratory Medicine, AdventHealth Orlando Hospital, Orlando, FL 32804, USA

6 Department of Pathology, College of Medicine, University of Central Florida, Orlando, FL 32804, USA

* Correspondence: C.Jeff.Chang.MD@AdventHealth.com; Tel.: +1-407-303-1932

$\dagger$ These authors contributed equally to this work.

Abstract: The 2017 ELN risk stratification has been widely adopted, but some studies have suggested the outcomes are heterogenous within the ELN risk groups and may be affected by other co-existing genetic mutations. This study evaluated the impact of DNA methylation regulatory gene (TET2, IDH1/2, DNMT3A, SETBP1) mutations (DMRGM) evaluated by NGS in the outcome of AML patients in each ELN risk group. A total of 114 patients were analyzed with a median follow-up of 12 months. Overall, 30.7\% (35/114) of patients had DMRGM. DMRGM status had no impact on CR rate in each ELN risk group. The OS, however, was significantly shorter in patients with DMRGM compared to those without DMRGM (median OS: 12 vs. 33 months, $p=0.0053$ ). Multivariate analysis showed DMRGM status was an independent unfavorable factor for OS (HR: 2.704, 95\% CI: 1.451-5.041, $p=0.0017)$. The adverse OS impact of DMRGM was only observed in the ELN favorable group (7 months vs. not reached, $p=0.0001$ ), but not in the intermediate or adverse group. Among the favorable group with DMRGM $(\mathrm{n}=16)$, DMRGM occurred predominantly in cases with mutated NPM1 (15/16, or 93.8\%). Our results suggest that DMRGM adversely impact the outcomes of ELN favorable group patients, particularly those with mutated NPM1. Further studies are warranted to confirm our observations.

Keywords: acute myeloid leukemia; DNA methylation regulatory gene mutations; DNMT3A; IDH1/2; NGS; TET2; 2017 ELN risk stratification

\section{Introduction}

Acute myeloid leukemia (AML) is a heterogeneous aggressive blood cell cancer which is the most common acute leukemia in adults [1]. Next-generation sequencing (NGS) has emerged as an important tool in the identification of mutated genes in AML [2-4]. Recently, large studies have identified multiple such gene mutations that significantly impact the prognostic outcomes of AML [5-8]. In 2017, the European Leukemia Net (ELN) stratified AML patients into three risk groups based on the presence or absence of specific chromosomal abnormalities and selected gene mutations [9]. As a result, the impact of 
NPM1, FLT3-ITD and CEBPA mutations was further defined based on the presence of other mutations such as RUNX1, ASXL1 and TP53. This has advanced prognosis and therapeutic options in AML. Some studies, however, have suggested that complete remission (CR) rates and outcomes are heterogenous within the 2017 ELN risk groups and may be affected by other co-existing genetic mutations [10-12].

One important class of mutations in AML regulates DNA methylation patterns. Genes such as DNMT3A, TET2, IDH1 and IDH2, collectively referred to here as DNA methylation regulatory gene mutations (DMRGM), have been shown to be associated with poor prognosis [5,11,13-18]. Others, however, have not shown similar prognostic impacts of such mutations of DMRGM in AML patients $[19,20]$. It is well established that IDH1 and 2 are mutually exclusively in AML [21]. In addition, few studies with a large number of AML patient have demonstrated that TET2 mutation is mutually exclusive with IDH1 and IDH2 mutations [18,22]. Based on these observations, it has been suggested that the mutations of DNA methylation regulatory genes may have similar biological and prognostic effects in AML $[6,15,22,23]$. Of note, a prior study by Ryotokuji $\mathrm{T}$ et al. in 2016, combining these DMRGM as one factor, revealed the unfavorable prognostic impact of DMRGM for overall survival (OS) among AML patients [24]. These observations prompted us to explore the prognostic impact of DMRGM in each group of the 2017 ELN risk group stratification.

\section{Materials and Methods}

\subsection{Patients}

Adult AML patients aged 18-75 who underwent intensive induction chemotherapy at our institution from 2017 to 2020 were screened for this study. All patients had bone marrow biopsies for morphologic evaluation, flow cytometry immunophenotyping, conventional karyotyping and next generation sequencing (NGS) study for AML-associated gene mutations at diagnosis. The diagnoses and classification of AML were based on the 2016 World Health Organization (WHO) classification of AML, and risk groups were assigned using the 2017 ELN risk stratification scheme [9,25]. Patients with treatment related-AML (t-AML) and acute promyelocytic leukemia (APL) were excluded. All patients in the study received intensive chemotherapy with or without FLT3 inhibitors as appropriate and/or hematopoietic stem cell transplantation (HSCT) based on standard protocols. The study was approved by the institutional review board.

\subsection{NGS Study and FLT3-ITD Measurement}

The NGS study was performed using a CLIA certified laboratory developed target panel covering 53 AML related genes, including ATM, AXSL1, BCOR, BCORL1, BRAF, CBL, CEBPA, CREBBP, CSF1R, CSF3R, CSF4R, DNMT3A, EZH2, FBWX7, FGFR4, FLT3ITD, FLT3-TKD, GATA1, GATA2, IDH1, IDH2, JAK2, KDM6A, KIT, KRAS, MPL, NF1, NOTCH2, NPM1, NRAS, PDGFRA, PDGGRB, PTPN11, RUNX1, SETBP1, SF3B1, SRSF2, STAG2, TET2, TP53, U2AF1, WT1, and ZRSR2. The panel sequenced all coding regions of the genes tested, not just known hot spots. Briefly, DNA was extracted from bone marrow aspirate or peripheral blood of each case using an Autopure extractor (Qiagen, Valencia, CA, USA) and was quantified using a Qubit DNA BR assay kit (Life Technologies, Carlsbad, CA, USA). The library was prepared using $250 \mathrm{ng}$ of DNA. Target enrichment was performed using oligonucleotide-based targeted capture (xGen Lockdown Custom Target Capture Probes, Integrated DNA Technologies, and SeqCap EZ Hybridization and Wash Kit, Roche NimbleGen, Inc. Pleasanton, CA, USA) of whole genome shotgun sequencing libraries (KAPA Hyper Prep Kit and Kapa Library Amplification Kit, KAPA Biosystems, Inc. Woburn, MA, USA). Sequencing of enriched libraries was performed in multiplex on the Illumina HiSeq 2500 using the paired-end, 101 base-pair configurations. The bioinformatic analysis and annotation was performed by Clinical Genomics Workspace (PierianDX, Creve Coeur, MO, USA).

Mutations were called if the variant allele frequency (fraction) was greater than $2.5 \%$ and greater than 30 supporting reads. FLT3-ITD was also tested by capillary electrophoresis 
provided by Neogenomics Laboratory (Fort Myers, FL, USA) since NGS could miss ITD with larger base pairs and could not quantitate ITD allele fraction to determine ELN risk groups. The ITD allele fraction was determined by dividing the area under the ITD peak by the area under the wild-type allele peak.

\subsection{Patient Group}

DMRGM were defined as mutations detected in at least one of the following genes: DNMT3A, TET2, IDH1, IDH2 or SETBP1. The patients were divided into 6 groups: groups 1 and 2 as ELN favorable group with or without DMRGM, groups 3 and 4 as ELN intermediate group with or without DMRGM, and groups 5 and 6 as ELN adverse group with or without DMRGM.

\subsection{Statistical Analyses}

The median follow-up for survival was calculated according to the Kaplan-Meier method [26]. Patient baseline characteristics between DNA methylation regulatory genes mutated or unmutated groups were performed by using the Mann-Whitney test for continuous variables and by using a chi-square test for categorical variables. The KaplanMeier method was used to estimate the distribution of OS in each group by the 2017 ELN risk stratification [27]. The log-rank test was used for univariate analysis to compare the OS difference between groups. Post hoc pairwise comparisons for the log-rank test with Sidak adjustment were performed to prevent type I error. The Cox proportional hazard regression model was used for multivariable analysis [28]. CR rates were compared by chi-square test or Fischer's exact test based on sample sizes. Two-tailed statistical significance at a level of 5\% was used for statistical analysis. All analyses were performed using SAS 9.4 (SAS Institute, Cary, NC, USA).

\section{Results}

\subsection{Patients' Characteristics}

A total of 114 patients were studied (Table 1$)$. There were 69 males $(60.5 \%)$ and 45 females (39.5\%) with a median age of 61.5 years (range, 19-75). The median follow-up was 12 months. Patients were nearly equally distributed among favorable, intermediate, and adverse per 2017 ELN. DMRGM were present in 30.7\% (35/114) of patients. Table 1 describes the clinical and laboratory features as well as AML classification of patients by DMRGM status. There were no significant differences in age, gender, white blood cell (WBC) counts, bone marrow (BM) blasts, peripheral blood (PB) blasts, or HSCT rate between DMRGM positive versus negative groups.

\subsection{Incidence of DMRGM}

Overall, we found DMRGM in $30.7 \%$ patients. Twenty-six patients had one mutation, eight patients had two, and one patient had three mutations, with no cases of four or more mutations. Among ELN favorable risk patients $(\mathrm{n}=37)$, a total of 21 DMRGM occurred in $16(43.2 \%)$ patients: $21.6 \%$ with DNMT3A; $13.5 \%$ with IDH2; $13.5 \%$ with TET2 and $8.1 \%$ with IDH1 mutation. Among the ELN intermediate risk group $(\mathrm{n}=38)$, a total of 16 DMRGM occurred in 12 (31.6\%) patients: $13.2 \%$ with DNMT3A; $7.9 \%$ with IDH2; 13.2\% with TET2 and 7.9\% with IDH1 mutation. Within the ELN adverse risk $(\mathrm{n}=39)$ group, a total of eight DMRGM occurred in seven (17.9\%) patients: $7.7 \%$ with DNMT3A; $5.1 \%$ with IDH2; $2.6 \%$ with TET2 and no patients with IDH mutation, and SETBP1 5.1\% (2/39). Table 2 summarizes the incidence of DMRGM in our cohort. These findings led to 16, 21, 12, 26, 7 and 32 patients classified as groups 1, 2, 3, 4, 5 and 6, respectively. DMRGM occurred more frequently in the ELN favorable group $(16 / 37 ; 43.2 \%)$ than the adverse group $(7 / 39$, $17.9 \%)(p=0.0164)$. However, the rates of DMRGM were not statistically significantly different between the favorable and intermediate groups or between the intermediate and adverse groups. 
Table 1. Clinical/laboratory characteristics and AML classification of patients according to DNA methylation regulatory gene mutation status.

\begin{tabular}{|c|c|c|c|c|}
\hline Characteristic & $\begin{array}{l}\text { All Patients } \\
(\mathrm{n}=114)\end{array}$ & $\begin{array}{c}\text { DMRGM * Positive } \\
(\mathrm{n}=35)\end{array}$ & $\begin{array}{l}\text { DMRGM Negative } \\
\qquad(\mathrm{n}=79)\end{array}$ & $p$-Value \\
\hline Age, years & & & & 0.0748 \\
\hline Median & 61.5 & 63.16 & 58.92 & \\
\hline IQR * & $(48.44,67.11)$ & $(56.29,69.31)$ & $(46.52,66.85)$ & \\
\hline Sex, No. (\%) & & & & 0.1859 \\
\hline Male & $69(60.53)$ & $18(51.43)$ & $51(64.56)$ & \\
\hline Female & $45(39.47)$ & $17(48.57)$ & $28(35.44)$ & \\
\hline $\mathrm{WBC}, 10^{3} / \mathrm{uL}$ & & & & 0.3363 \\
\hline Median & 7.5 & 11.57 & 7.05 & \\
\hline IQR & $(2,37.57)$ & $(2.1,55.8)$ & $(1.93,30)$ & \\
\hline Missing Values & 0 & 0 & 0 & \\
\hline BM blasts (\%) & & & & 0.8825 \\
\hline Median & 51 & 58 & 47.6 & \\
\hline IQR & $(25,72)$ & $(25,73.2)$ & $(25,69.2)$ & \\
\hline Missing values & 0 & 0 & 0 & \\
\hline PB blasts (\%) & & & & 0.2977 \\
\hline Median & 18 & 18 & 18 & \\
\hline IQR & $(1,60)$ & $(0,60)$ & $(2,60)$ & \\
\hline Missing values & 8 & 2 & 6 & \\
\hline Platelet counts, $10^{3} / \mathrm{uL}$ & & & & 0.303 \\
\hline Median & 52 & 53.5 & 52 & \\
\hline IQR & $(24,89)$ & $(29,100)$ & $(23,89)$ & \\
\hline Missing values & 1 & 1 & 0 & \\
\hline Hemoglobin, g/dL & & & & 0.3195 \\
\hline Median & 8 & 8.2 & 7.9 & \\
\hline $\mathrm{QR}$ & $(7,9.5)$ & $(7.2,9.5)$ & $(6.5,9.5)$ & \\
\hline Missing values & 0 & 0 & 0 & \\
\hline $\begin{array}{l}2017 \text { ELN risk, } \\
\text { No. }(\%)\end{array}$ & & & & 0.057 \\
\hline Favorable & $37(32.46)$ & $16(45.71)$ & $21(26.58)$ & \\
\hline Intermediate & $38(33.33)$ & $12(34.29)$ & $26(32.92)$ & \\
\hline Adverse & $39(34.21)$ & $7(20.00)$ & $32(40.50)$ & \\
\hline $\mathrm{HSCT}^{*}$, No. $(\%)$ & & & & 0.4019 \\
\hline Not Received & $65(57.02)$ & $22(62.86)$ & $43(54.43)$ & \\
\hline Received & $49(42.98)$ & $13(37.14)$ & $36(45.57)$ & \\
\hline Classification of AML, No. (\%) & & & & \\
\hline AML with t(8;21)(q22;q22.1);RUNX1-RUNX1T1 & $7(6.14 \%)$ & $0(0.00 \%)$ & $7(8.86 \%)$ & \\
\hline AML with inv(16)(p13.1q22) or $\mathrm{t}(16 ; 16)(\mathrm{p} 13.1 ; \mathrm{q} 22) ; \mathrm{CBFB}-\mathrm{MYH} 11$ & $7(6.14 \%)$ & $1(2.86 \%)$ & $6(7.59 \%)$ & \\
\hline AML with t(9;11)(p21.3;q23.3);MLLT3-KMT2A & $2(1.75 \%)$ & $2(5.71 \%)$ & $0(0.00 \%)$ & \\
\hline AML with mutated NPM1 & $25(21.93 \%)$ & $16(45.71 \%)$ & $9(11.39 \%)$ & \\
\hline AML with biallelic mutations of CEBPA & $2(1.75 \%)$ & $0(0.00 \%)$ & $2(2.53 \%)$ & \\
\hline AML with myelodysplasia-related changes & $31(27.19 \%)$ & $9(25.71 \%)$ & $22(27.85 \%)$ & \\
\hline AML, NOS & $40(35.09 \%)$ & $7(20.00 \%)$ & $33(41.77 \%)$ & \\
\hline
\end{tabular}

* Abbreviation: DMRGM; DNA methylation regulatory gene mutations, HSCT; Hematopoietic stem cell transplantation, IQR; Interquartile range, NO.; Number.

Table 2. Incidence of DNA methylation regulatory gene mutations in the whole cohort and among ELN risk groups.

\begin{tabular}{cccccc}
\hline & DNMT3A & IDH1 & IDH2 & TET2 & SETBP1 \\
\hline Whole AML cohort $(\mathrm{n}=114)$ & $14.0 \%(16 / 114)$ & $5.3 \%(6 / 114)$ & $8.8 \%(10 / 114)$ & $9.6 \%(11 / 114)$ & $1.8 \%(2 / 114)$ \\
Favorable risk $(\mathrm{n}=37)$ & $21.6 \%(8 / 37)$ & $8.1 \%(3 / 37)$ & $13.5 \%(5 / 37)$ & $13.5 \%(5 / 37)$ & $0.0 \%(0 / 37)$ \\
Intermediate risk $(\mathrm{n}=38)$ & $13.2 \%(5 / 38)$ & $7.9 \%(3 / 38)$ & $7.9 \%(3 / 38)$ & $13.2 \%(5 / 38)$ & $0.0 \%(0 / 38)$ \\
Adverse risk $(\mathrm{n}=39)$ & $7.7 \%(3 / 39)$ & $0.0 \%(0 / 39)$ & $5.1 \%(2 / 39)$ & $2.6 \%(1 / 39)$ & $5.1 \%(2 / 39)$ \\
\hline
\end{tabular}

\subsection{Survival Analysis}

Among the entire cohort of patients, the OS of patients with DMRGM was significantly worse than that of patients without DMRGM (medial OS: 12 months vs. 33 months, $p=0.0053$, Figure 1A). Multivariate analysis showed that DMRGM status was an independent unfavorable prognostic factor for OS (hazard ratio (HR): $2.704,95 \%$ confidence interval (CI): 1.451-5.041, $p=0.0017$, Table 3a). 


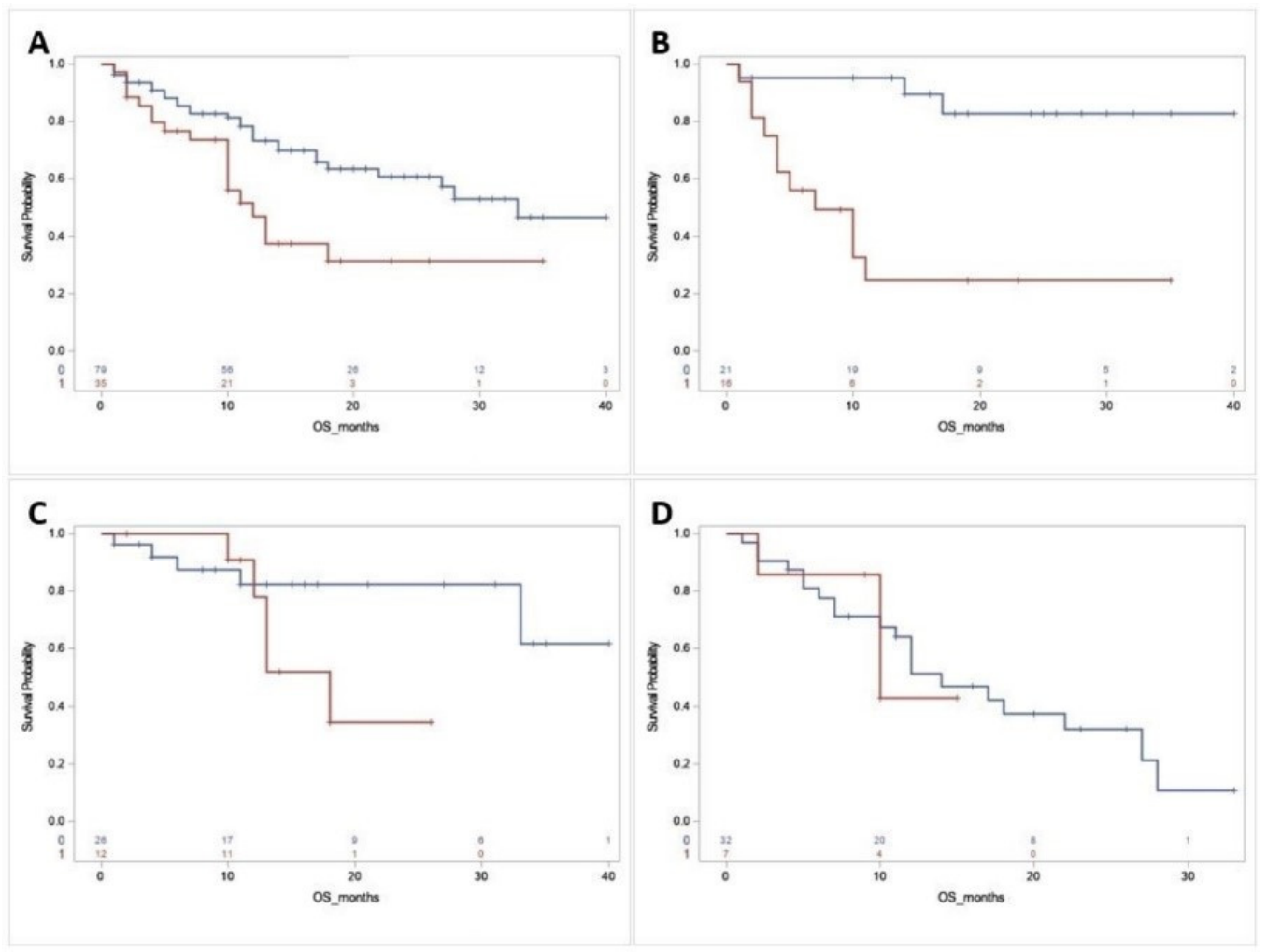

Figure 1. Overall survival (OS) rates by DNA methylation mutation. Red Line: DNA methylation regulatory gene (DMRGM) mutation positive. Blue Line: DMRGM negative. (A) OS rate for all AML cases by DMRGM positive versus negative (medial OS: 12 months vs. 33 months, $p=0.0053$ ). (B) OS rate for 2017 ELN favorable group by DMRGM positive versus negative (median OS: 7 months vs. not reached, $p=0.0001$ ). (C) OS rate for 2017 ELN intermediate group by DMRGM positive versus negative $(p=0.1172$ ). (D) OS rate for 2017 ELN adverse group by DMRGM positive versus negative $(p=0.7773)$.

Table 3. Multivariate analysis of prognostic factors for overall survival.

\begin{tabular}{|c|c|c|c|c|}
\hline \multicolumn{5}{|c|}{ (a) Cox hazard proportional models in all AML patients $(n=114)$} \\
\hline Variables & & HR * & $95 \% \mathrm{CI} *$ & $p$-Value \\
\hline DMRGM * & $\begin{array}{c}\text { Yes } \\
\text { (Reference, No) }\end{array}$ & 2.704 & $(1.451,5.041)$ & 0.0017 \\
\hline 2017 ELN risk & $\begin{array}{c}\text { Intermediate } \\
\text { High } \\
\text { (Reference, Favor) }\end{array}$ & $\begin{array}{c}0.93 \\
2.911\end{array}$ & $\begin{array}{l}(0.392,2.208) \\
(1.379,6.186)\end{array}$ & $\begin{array}{l}0.8693 \\
0.0051\end{array}$ \\
\hline Age & $\begin{array}{c}65 \text { and over } \\
\text { (Reference, under 65) }\end{array}$ & 1.124 & $(0.592,2.135)$ & 0.7205 \\
\hline HSCT * & $\begin{array}{c}\text { Yes } \\
\text { (Reference, No) }\end{array}$ & 0.37 & $(0.19,0.719)$ & 0.0034 \\
\hline \multicolumn{5}{|c|}{ (b) Cox hazard proportional models for 2017 ELN favor risk group $(n=37)$} \\
\hline Variables & & HR & $95 \% \mathrm{CI}$ & $p$-Value \\
\hline DMRGM & $\begin{array}{c}\text { Yes } \\
\text { (Reference, No) }\end{array}$ & 6.882 & $(1.24,38.184)$ & 0.0274 \\
\hline Age & $\begin{array}{c}65 \text { and over } \\
\text { (Reference, under 65) }\end{array}$ & 1.235 & $(0.314,4.857)$ & 0.763 \\
\hline HSCT & $\begin{array}{c}\text { Yes } \\
\text { (Reference, No) }\end{array}$ & 0.534 & $(0.161,1.77)$ & 0.3049 \\
\hline NPM1 Mutation & $\begin{array}{c}\text { Yes } \\
\text { (Reference No) }\end{array}$ & 1.629 & $(0.251,10.589)$ & 0.6092 \\
\hline $\begin{array}{l}\text { FLT3-ITD } \\
\text { Mutation }\end{array}$ & $\begin{array}{c}\text { Yes } \\
\text { (Reference No) }\end{array}$ & 1.188 & $(0.363,3.891)$ & 0.7761 \\
\hline
\end{tabular}

* Abbreviation: CI; Confidence interval, DMRGM; DNA methylation regulatory gene mutations, HR; Hazard ratio, HSCT; Hematopoietic stem cell transplantation. 
We subsequently examined the impact of DMRGM on survival within each 2017 ELN risk group. For the ELN favorable group $(n=37)$, the median OS of patients with DMRGM was significantly shorter than those without DMRGM (7 months vs. not reached, $p=0.0001$, Figure 1B). Of note, among the ELN favorable group, patients with mutated NPM1 I ( $\mathrm{n}=21)$ DMRGM showed similar impact on median OS (DMRGM vs. no DMRGM: 7 months vs. not reached, $p=0.016$ ). In multivariate analysis, the DMRGM status remained an independent unfavorable prognostic factor for OS (HR: 6.882, 95\% CI: 1.24-38.184, $p=0.0274$, Table 3b). In contrast, DMRGM showed no significant impact on OS in either the ELN intermediate group or ELN adverse group (Figure 1C,D). Of importance, the median OS of the ELN favorable group with DMRGM was significantly shorter than that of the ELN intermediate group (7 months vs. not reached, $p=0.0078$, Figure 2 ) and also appeared shorter than that of the ELN adverse group, although not statistically significant (7 vs. 12 months, $p=0.9937$, Figure 2).

\subsection{Genetic Association of DMRGM with Other Mutations in the 2017 ELN Favorable Risk Group}

Among the ELN favorable group with DMRGM ( $\mathrm{n}=16)$, DMRGM occurred predominantly in cases with mutated NPM1 (15/16, or $93.8 \%$, Figure 3$)$. The remaining one case concurred with CBFB-MYH1 fusion (Figure 3). The DMRGM in mutated NPM1 cases appeared independent of FLT3-ITD mutations (eight patients had FLT3-ITD ${ }^{\text {low }}$, and seven patients were without FLT3-ITD).

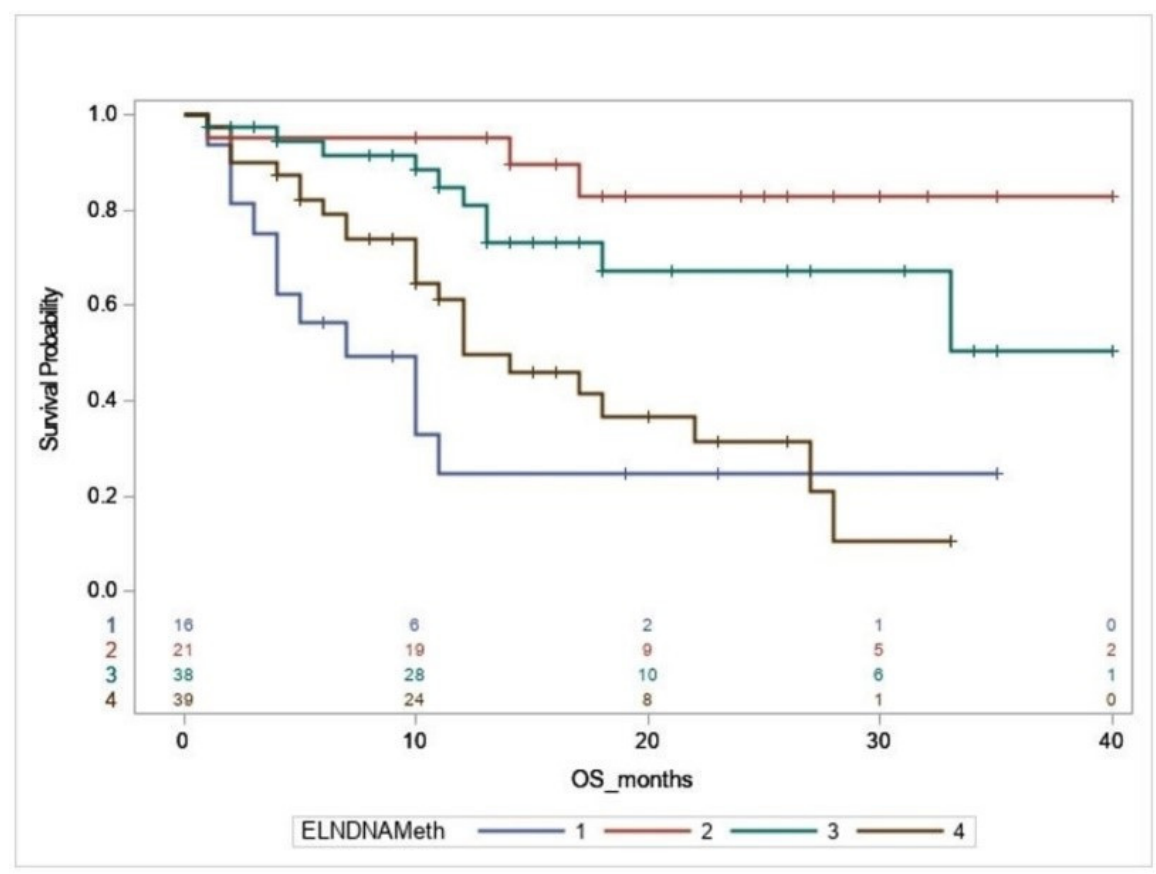

Figure 2. Overall survival (OS) rates in ELN favorable group with and without DNA-MR, ELN intermediate, and ELN adverse group. Kaplan-Meier curves for OS in ELN favorable with DMRGM (Blue line: 1, median OS: 7 months), ELN favorable without DMRGM (Red line: 2, median OS: Not reached), ELN intermediate (Green line: 3, median OS: Not reached) and ELN adverse group (Brown line: 4, median OS: 12 months). The OS of the ELN favorable with DMRGM was significantly shorter than that of the favorable group without DMRGM $(p=0.0001)$ or the ELN intermediate group ( $p=0.0078)$. The median OS of ELN favorable group with DMRGM was not significantly different from that of ELN adverse group $(p=0.9937)$. 


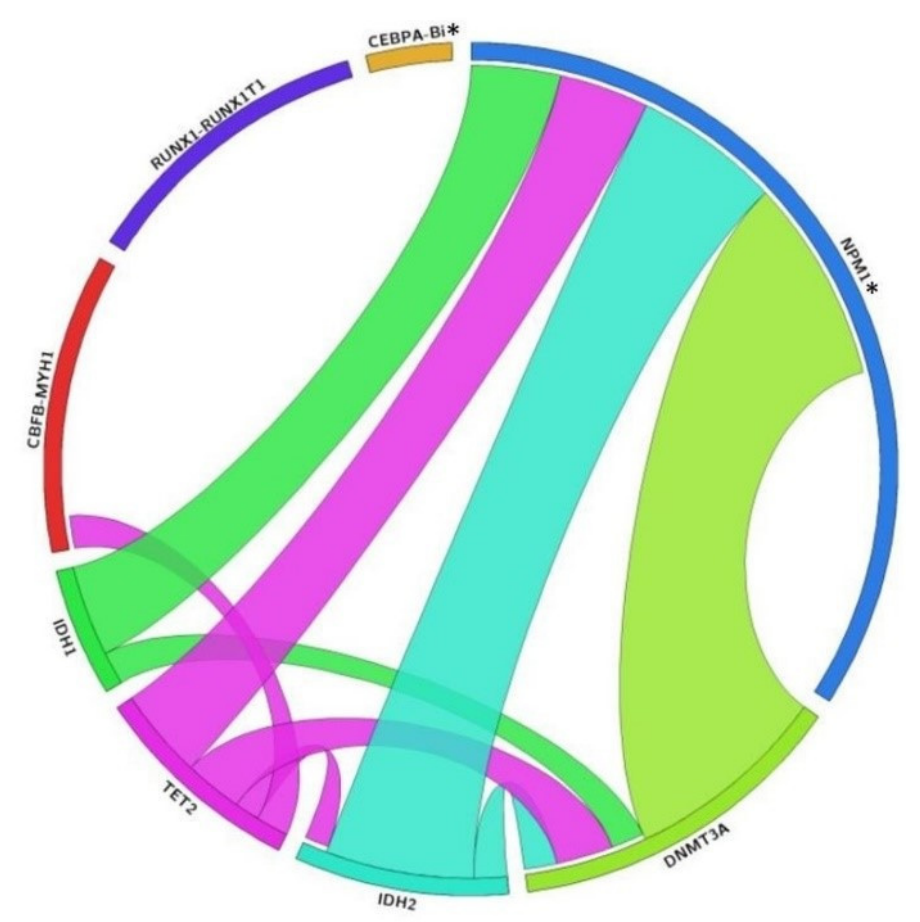

Figure 3. Mutational profile of 2017 favorable AML group in our cohort by using Circos plot model. The thickness of connection for each mutation is proportional to the number of co-occurring cases. Among 2017 favorable mutations, only NPM1 mutation significantly co-occurred with DNA methylation-related gene mutations (including DNMT3A, TET2, IDH1, and IDH2). * Abbreviation: CEBPA-Bi; Biallelic mutated CEBPA, NPM1; Mutated NPM1 without FLT3-ITD or with FLT3-ITD ${ }^{\text {low }}$.

\section{Discussion}

The results of this study indicate that DMRGM commonly occur in AML and they adversely impact the prognosis of AML patients based on the 2017 ELN risk classification. The impact of these mutations was mainly seen in the favorable risk group, particularly those with NPM1 mutation, while they had no impact on the ELN intermediate or adverse risk category.

Although the prognostic impact of DMRGM as a group of genes on AML patients has not been extensively studied, multiple studies on individual genes involving DNA methylation regulations correlate with our findings. Several studies suggest that DNMT3A adversely impacts OS effect on AML patients $[6,14,15]$. In a meta-analysis of $4500 \mathrm{AML}$ patients by Shivarov et al., DNMT3A mutations showed a significantly worse prognosis, particularly in patients with cytogenetically normal AML (CN-AML) [29]. IDH1/2 mutations have also been shown to adversely impact OS in AML patients [16,17]. In a recent meta-analysis, IDH1/2 mutations showed no OS affect in the whole AML population; however, IDH1 mutation conferred a worse OS in patients with CN-AML (OS: HR, 1.21; 95\% CI, 1.01-1.46) [30]. Additionally, similar to our findings, others have shown that IDH mutations tended to occur with NPM1 but not FLT3-ITD mutations [5,17]. Furthermore, some studies reported that the negative impact of $I D H 1$ and 2 mutations was only seen in mutated NPM1 with wild-type FLT3, but not in other AML patients [17,31]. With respect to TET2 mutations, a meta-analysis by Liu et al. in 2552 AML patients showed that it was associated as an adverse prognostic indicator only in CN-AML (OS: HR, 1.43, 95\% CI: 1.16-1.75, $p=0.001$ [32]. Tian et al. evaluated the impact of TET2 in 373 adults with CN-AML patients. They reported that TET2 mutation was an unfavorable prognostic factor leading to shorter median OS as compared to wild-type TET2, particularly in FLT3-ITD negative, NPM1 positive patients (9.5 vs. 32.2 months, $p=0.013$ ) [33]. Though it is well established that mutated NPM1 has favorable outcomes in AML, our results and the above studies suggest that DMRGM may adversely impact the OS of patients with mutated 
NPM1. Although many of the above studies considered the effects of cytogenetic findings and NPM1 mutation, none of these studies specifically looked into the impact of these gene mutations among different ELN risk groups.

Our approach of considering DMRGM as a group is similar to the study by Ryotokuji et al., in which the investigators integrated four genes (IDH1/2, TET2 and DNMT3A) involving DNA methylation regulation as a group and analyzed its prognostic impact on AML. In their study, cases with DMRGM had a significantly poorer OS than those without DMRGM in all cases of AML, in agreement with our findings [24]. However, this study did not evaluate the prognostic effect of DMRGM by ELN risk stratification. Our study further found that the adverse impact of DMRGM on AML patients was only in patients in the ELN favorable risk group. However, the mechanisms leading to the adverse impact remain unclear and require future studies. Of note, the adverse impact appears not associated with the complete response $(\mathrm{CR})$ rate. In the entire cohort, the CR rate of patients with DMRGM was not different from the patients without DMRGM. Similarly, DMRGM status did not impact the CR rate within each ELN risk group.

In contrast to our observation, some studies have shown that mutations of DNA methylation regulatory genes may not impact the prognosis of AML patients. For example, Gaidzik et al. reported no significant survival impact of DNMT3A mutation in a cohort of 1770 adult AML patients [19]. Shen et al. stated that DNMT3A, but not IDH1/2, mutations adversely impacted OS in a cohort of 605 AML patients [20]. Moreover, Mason et al. reported that NPM1-mutated AML patients with TET2, IDH1/2 mutations had better OS than NPM1-mutated patients without such mutations [34]. The mechanisms leading to these discrepancies remain uncertain. Further studies with larger sample sizes are needed to fully illustrate the prognostic impact of DMRGM in AML.

Grouping DMRGM as a functional group of genes to study the impact on the survival of AML patients can be controversial. For example, SETBP1 mutations in AML are relatively uncommon compared to TET2, IDH1/2 and DNMT3A, and the prognostic impact of SETBP1 mutation has not been well documented. However, it is well established that IDH1, IDH2 and TET2 are usually mutually exclusive in AML [5,18,22,35]. In addition, mutations of these three genes have similar epigenetic impacts leading to global DNA hypermethylation [22,36-38]. DNMT3A has also been reported to play an important role in DNA methylation, and several studies have demonstrated a correlation between DNMT3A mutation and DNA methylation, although the function and biological consequences of DNMT3A mutations have yet to be fully elucidated [38-40]. Additionally, particular mutations of DNMT3A may have different effects on methylation regulation. Some studies have suggested that $S E T B P 1$ is involved in methylation [41,42]. In the current study, only two patients had SETBP1 mutations, both in the ELN adverse risk group, and DMRGM did not impact survival outcome in this group. Future studies, particularly for SETBP1-mutated patients, are needed to validate the approach of considering DMRGM as a functional group.

Among the ELN favorable risk group, the cases with mutated NPM1 show strong concurrence with DMRGM in our study. This finding agrees with previous studies which have reported that DNMA3A,IDH1/2 and/or TET2 frequently co-occurred with NPM1 mutation in AML patients $[4,5,43]$. The study by Papaemmanuil et al. revealed that $73 \%$ (319 of 436) of NPM1-mutated AML patients are positive for mutations in at least one of the following genes: DNMT3A, IDH1, IDH2, and TET2 [5]. Our findings confirm that DMRGM frequently concur with NPM1 mutation and suggest these mutations may adversely impact OS.

Although our study suffers from limitations of small sample size, particularly only 37 patients in the ELN favorable group with 16 of them carrying DMRGM, and retrospective analysis, it can have important clinical implications if confirmed by others. The current recommendation is to advise against allogeneic stem cell transplantation in patients with favorable risk disease in CR1. Thus, ELN favorable risk patients, particularly those defined by mutated NPM1, with DMRGM may not receive adequate treatment. Our findings suggest the importance of including DNA methylation regulatory genes in the targeted 
NGS panel along with the genes used to define current ELN risk groups to further evaluate the clinical significance of DMRGM.

\section{Conclusions}

In conclusion, our results indicate that DMRGM are common in AML patients and adversely impact the prognosis of AML patients, particularly those in the 2017 ELN favorable risk group defined by mutated NPM1. The latter patients had OS similar to that of patients in the ELN adverse risk group. Further studies with a large sample size are warranted to confirm our observations.

Author Contributions: Conceptualization, C.-C.C., J.C.V., R.P. and S.M.; methodology, C.-C.C. and J.Y.; formal analysis, J.Y. and Y.D.; investigation, J.Y. and J.S.; data curation, Y.D.; writing-original draft preparation, J.Y. and J.S.; writing-review and editing, C.-C.C., J.C.V., S.M.; visualization, J.Y. and Y.D.; supervision, C.-C.C.; project administration, C.-C.C.; funding acquisition, not applicable. All authors have read and agreed to the published version of the manuscript.

Funding: This research received no external funding.

Institutional Review Board Statement: The study was conducted according to the guidelines of the Declaration of Helsinki, and approved by the Institutional Review Board of AdventHealth Orlando (protocol code \#1337865, approval number for studies: 200 patients, and date of approval: 24 January 2020).

Informed Consent Statement: Patient consent was waived due to the retrospective design with IRB approval. Not applicable.

Data Availability Statement: Not applicable.

Conflicts of Interest: All authors declare no conflict of interest.

\section{References}

1. Siegel, R.L.; Miller, K.D.; Jemal, A. Cancer statistics, 2017. CA Cancer J. Clin. 2017, 67, 7-30. [CrossRef]

2. Ley, T.J.; Mardis, E.R.; Ding, L.; Fulton, B.; McLellan, M.D.; Chen, K.; Dooling, D.; Dunford-Shore, B.H.; McGrath, S.; Hickenbotham, M.; et al. DNA sequencing of a cytogenetically normal acute myeloid leukemia genome. Nature 2008, 456, 66-72. [CrossRef] [PubMed]

3. Mardis, E.R.; Ding, L.; Dooling, D.J.; Larson, D.E.; McLellan, M.D.; Chen, K.; Koboldt, D.C.; Fulton, R.S.; Delehaunty, K.D.; McGrath, S.D.; et al. Recurring mutations found by sequencing an acute myeloid leukemia genome. N. Engl. J. Med. 2009, 361, 1058-1066. [CrossRef]

4. Cancer Genome Atlas Research Network; Ley, T.J.; Miller, C.; Ding, L.; Raphael, B.J.; Mungall, A.J.; Robertson, A.G.; Hoadley, K.; Triche, T.J., Jr.; Laird, P.W.; et al. Genomic and epigenomic landscapes of adult de novo acute myeloid leukemia. N. Engl. J. Med. 2013, 368, 2059-2074. [CrossRef] [PubMed]

5. Papaemmanuil, E.; Gerstung, M.; Bullinger, L.; Gaidzik, V.I.; Paschka, P.; Roberts, N.D.; Potter, N.E.; Heuser, M.; Thol, F.; Bolli, N.; et al. Genomic classification and prognosis in acute myeloid leukemia. N. Engl. J. Med. 2016, 374, 2209-2221. [CrossRef]

6. Patel, J.P.; Gönen, M.; Figueroa, M.E.; Fernandez, H.; Sun, Z.; Racevskis, J.; Van Vlierberghe, P.; Dolgalev, I.; Thomas, S.; Aminova, O.; et al. Prognostic relevance of integrated genetic profiling in acute myeloid leukemia. N. Engl. J. Med. 2012, 366, 1079-1089. [CrossRef] [PubMed]

7. Marcucci, G.; Haferlach, T.; Döhner, H. Molecular genetics of adult acute myeloid leukemia: Prognostic and therapeutic implications. J. Clin. Oncol. 2011, 29, 475-486. [CrossRef]

8. Tsai, C.-H.; Hou, H.-A.; Tang, J.-L.; Liu, C.-Y.; Lin, C.-C.; Chou, W.-C.; Tseng, M.-H.; Chiang, Y.-C.; Kuo, Y.-Y.; Liu, M.-C.; et al. Genetic alterations and their clinical implications in older patients with acute myeloid leukemia. Leukemia 2016, 30, 1485-1492. [CrossRef] [PubMed]

9. Döhner, H.; Estey, E.; Grimwade, D.; Amadori, S.; Appelbaum, F.R.; Büchner, T.; Dombret, H.; Ebert, B.L.; Fenaux, P.; Larson, R.A.; et al. Diagnosis and management of AML in adults: 2017 ELN recommendations from an international expert panel. Blood 2017, 129, 424-447. [CrossRef]

10. Eisfeld, A.-K.; Kohlschmidt, J.; Mims, A.; Nicolet, D.; Walker, C.J.; Blachly, J.S.; Carroll, A.J.; Papaioannou, D.; Kolitz, J.E.; Powell, B.E.; et al. Additional gene mutations may refine the 2017 European LeukemiaNet classification in adult patients with de novo acute myeloid leukemia aged $<60$ years. Leukemia 2020, 34, 3215-3227. [CrossRef]

11. Eisfeld, A.-K.; Kohlschmidt, J.; Mrózek, K.; Blachly, J.S.; Walker, C.J.; Nicolet, D.; Orwick, S.; Maharry, S.E.; Carroll, A.J.; Stone, R.M.; et al. Mutation patterns identify adult patients with de novo acute myeloid leukemia aged 60 years or older who respond favorably to standard chemotherapy: An analysis of Alliance studies. Leukemia 2018, 32, 1338-1348. [CrossRef] 
12. Huang, S.-C.; Hou, H.-A.; Tsai, C.-H.; Chou, W.-C.; Tang, J.-L.; Yao, M.; Ko, B.-S.; Tien, F.-M.; Kuo, Y.-Y.; Tseng, M.-H.; et al. Re-examination of 2017 ELN risk classification by a cohort of 739 de novo aml patients in Taiwan: Co-occurring poor-risk mutations may further predict outcome in FLT3-ITD patients. Blood 2018, 132, 3977. [CrossRef]

13. Metzeler, K.H.; Herold, T.; Rothenberg-Thurley, M.; Amler, S.; Sauerland, M.C.; Görlich, D.; Schneider, S.; Konstandin, N.P.; Dufour, A.; Bräundl, K.; et al. Spectrum and prognostic relevance of driver gene mutations in acute myeloid leukemia. Blood 2016, 128, 686-698. [CrossRef] [PubMed]

14. Ley, T.J.; Ding, L.; Walter, M.J.; McLellan, M.D.; Lamprecht, T.L.; Larson, D.E.; Kandoth, C.; Payton, J.E.; Baty, J.; Welch, J.J.; et al. DNMT3A mutations in acute myeloid leukemia. N. Engl. J. Med. 2010, 363, 2424-2433. [CrossRef]

15. Ribeiro, A.F.T.; Pratcorona, M.; Erpelinck-Verschueren, C.; Rockova, V.; Sanders, M.; Abbas, S.; Figueroa, M.E.; Zeilemaker, A.; Melnick, A.; Löwenberg, B.; et al. Mutant DNMT3A: A marker of poor prognosis in acute my-eloid leukemia. Blood 2012, 119, 5824-5831. [CrossRef]

16. Abbas, S.; Lugthart, S.; Kavelaars, F.; Schelen, A.; Koenders, J.; Zeilemaker, A.; Van Putten, W.J.L.; Rijneveld, A.; Löwenberg, B.; Valk, P. Acquired mutations in the genes encoding IDH1 and IDH2 both are recurrent aberrations in acute myeloid leukemia: Prevalence and prognostic value. Blood 2010, 116, 2122-2126. [CrossRef] [PubMed]

17. Paschka, P.; Schlenk, R.F.; Gaidzik, V.I.; Habdank, M.; Krönke, J.; Bullinger, L.; Späth, D.; Kayser, S.; Zucknick, M.; Götze, K.; et al. IDH1 and IDH2 mutations are frequent genetic alterations in acute myeloid leukemia and confer adverse prognosis in cytogenetically normal acute myeloid leukemia with NPM1 mutation without FLT3 internal tandem duplication. J. Clin. Oncol. 2010, 28, 3636-3643. [CrossRef] [PubMed]

18. Chou, W.-C.; Chou, S.-C.; Liu, C.-Y.; Chen, C.-Y.; Hou, H.-A.; Kuo, Y.-Y.; Lee, M.-C.; Ko, B.-S.; Tang, J.-L.; Yao, M.; et al. TET2 mutation is an unfavorable prognostic factor in acute myeloid leukemia patients with intermediate-risk cytogenetics. Blood 2011, 118, 3803-3810. [CrossRef] [PubMed]

19. Gaidzik, V.I.; Schlenk, R.F.; Paschka, P.; Stölzle, A.; Späth, D.; Kuendgen, A.; Von Lilienfeld-Toal, M.; Brugger, W.; Derigs, H.G.; Kremers, S.; et al. Clinical impact of DNMT3A mutations in younger adult patients with acute myeloid leukemia: Results of the AML Study Group (AMLSG). Blood 2013, 121, 4769-4777. [CrossRef]

20. Shen, Y.; Zhu, Y.-M.; Fan, X.; Shi, J.-Y.; Wang, Q.-R.; Yan, X.-J.; Gu, Z.-H.; Wang, Y.-Y.; Chen, B.; Jiang, C.-L.; et al. Gene mutation patterns and their prognostic impact in a cohort of 1185 patients with acute myeloid leukemia. Blood 2011, 118, 5593-5603. [CrossRef]

21. Cairns, R.A.; Mak, T.W. Oncogenic isocitrate dehydrogenase mutations: Mechanisms, models, and clinical opportunities. Cancer Discov. 2013, 3, 730-741. [CrossRef]

22. Figueroa, M.E.; Abdel-Wahab, O.; Lu, C.; Ward, P.; Patel, J.; Shih, A.; Li, Y.; Bhagwat, N.; VasanthaKumar, A.; Fernandez, H.F.; et al. Leukemic IDH1 and IDH2 mutations result in a hypermethylation phenotype, disrupt TET2 function, and impair hematopoietic differentiation. Cancer Cell. 2010, 18, 553-567. [CrossRef] [PubMed]

23. Rakheja, D.; Konoplev, S.; Medeiros, L.J.; Chen, W. IDH mutations in acute myeloid leukemia. Hum. Pathol. 2012, 43, 1541-1551. [CrossRef] [PubMed]

24. Ryotokuji, T.; Yamaguchi, H.; Ueki, T.; Usuki, K.; Kurosawa, S.; Kobayashi, Y.; Kawata, E.; Tajika, K.; Gomi, S.; Kanda, J.; et al. Clinical characteristics and prognosis of acute myeloid leukemia associated with DNA-methylation regulatory gene mutations. Haematologica 2016, 101, 1074-1081. [CrossRef] [PubMed]

25. Arber, D.A.; Orazi, A.; Hasserjian, R.; Thiele, J.; Borowitz, M.J.; Le Beau, M.M.; Bloomfield, C.D.; Cazzola, M.; Vardiman, J.W. The 2016 revision to the World Health Organization classification of myeloid neoplasms and acute leukemia. Blood 2016, 127, 2391-2405. [CrossRef]

26. Betensky, R.A. Measures of follow-up in time-to-event studies: Why provide them and what should they be? Clin. Trials. 2015, 12, 403-408. [CrossRef]

27. Kaplan, E.L.; Meier, P. Nonparametric estimation from incomplete observations. J. Am. Stat. Assoc. 1958, 53, 457-481. [CrossRef]

28. Therneau, T.M.; Grambsch, P.M. The cox model. In Modeling Survival Data: Extending the Cox Model. Statistics for Biology and Health; Therneau, T.M., Grambsch, P.M., Eds.; Springer: Cham, Switzerland, 2000; pp. 39-77. [CrossRef]

29. Shivarov, V.; Gueorguieva, R.; Stoimenov, A.; Tiu, R. DNMT3A mutation is a poor prognosis biomarker in AML: Results of a meta-analysis of 4500 AML patients. Leuk. Res. 2013, 37, 1445-1450. [CrossRef]

30. Xu, Q.; Li, Y.; Lv, N.; Jing, Y.; Xu, Y.; Li, Y.; Li, W.; Yao, Z.; Chen, X.; Huang, S.; et al. Correlation between isocitrate dehydrogenase gene aberrations and prognosis of patients with acute myeloid leukemia: A systematic review and meta-analysis. Clin. Cancer Res. Off. J. Am. Assoc. Cancer Res. 2017, 23, 4511-4522. [CrossRef]

31. Ravandi, F.; Patel, K.; Luthra, R.; Faderl, S.; Konopleva, M.; Kadia, T.; Brandt, M.; Pierce, S.; Kornblau, S.; Andreeff, M.; et al. Prognostic significance of alterations in IDH enzyme isoforms in patients with AML treated with high-dose cytarabine and idarubicin. Cancer 2012, 118, 2665-2673. [CrossRef]

32. Liu, W.-J.; Tan, X.-H.; Luo, X.-P.; Guo, B.-P.; Wei, Z.-J.; Ke, Q.; He, S.; Cen, H. Prognostic significance of Tet methylcytosine dioxygenase 2 (TET2) gene mutations in adult patients with acute myeloid leukemia: A meta-analysis. Leuk. Lymphoma. 2014, 55, 2691-2698. [CrossRef]

33. Tian, X.; Xu, Y.; Yin, J.; Tian, H.; Chen, S.; Wu, D.; Sun, A. TET2 gene mutation is unfavorable prognostic factor in cytogenetically normal acute myeloid leukemia patients with NPM1+ and FLT3-ITD- mutations. Int. J. Hematol. 2014, 100, 96-104. [CrossRef] [PubMed] 
34. Mason, E.F.; Kuo, F.C.; Hasserjian, R.P.; Seegmiller, A.C.; Pozdnyakova, O. A distinct immunophenotype identifies a subset of NPM1-mutated AML with TET2 or IDH1/2 mutations and improved outcome. Am. J. Hematol. 2018, 93, 504-510. [CrossRef] [PubMed]

35. Gaidzik, V.I.; Paschka, P.; Späth, D.; Habdank, M.; Köhne, C.-H.; Germing, U.; Von Lilienfeld-Toal, M.; Held, G.; Horst, H.-A.; Haase, D.; et al. TET2 mutations in acute myeloid leukemia (AML): Results from a comprehensive genetic and clinical analysis of the AML study group. J. Clin. Oncol Off. J. Am. Soc. Clin. Oncol. 2012, 30, 1350-1357. [CrossRef] [PubMed]

36. Ward, P.; Patel, J.; Wise, D.R.; Abdel-Wahab, O.; Bennett, B.D.; Coller, H.A.; Cross, J.R.; Fantin, V.R.; Hedvat, C.V.; Perl, A.E.; et al. The common feature of leukemia-associated IDH1 and IDH2 mutations is a neomorphic enzyme activity converting alpha-ketoglutarate to 2-hydroxyglutarate. Cancer Cell. 2010, 17, 225-234. [CrossRef]

37. Dang, L.; White, D.W.; Gross, S.; Bennett, B.D.; Bittinger, M.A.; Driggers, E.M.; Fantin, V.R.; Jang, H.G.; Jin, S.; Keenan, M.C.; et al Cancer-associated IDH1 mutations produce 2-hydroxyglutarate. Nature 2009, 462, 739-744. [CrossRef]

38. Im, A.P.; Sehgal, A.R.; Carroll, M.P.; Smith, B.D.; Tefferi, A.; E Johnson, D.; Boyiadzis, M. DNMT3A and IDH mutations in acute myeloid leukemia and other myeloid ma-lignancies: Associations with prognosis and potential treatment strategies. Leukemia 2014, 28, 1774-1783. [CrossRef]

39. Hájková, H.; Marková, J.; Haškovec, C.; Šárová, I.; Fuchs, O.; Kostečka, A.; Cetkovský, P.; Michalová, K.; Schwarz, J. Decreased DNA methylation in acute myeloid leukemia patients with DNMT3A mutations and prognostic implications of DNA methylation. Leuk. Res. 2012, 36, 1128-1133. [CrossRef]

40. Yan, X.-J.; Xu, J.; Gu, Z.-H.; Pan, C.-M.; Lu, G.; Shen, Y.; Shi, J.-Y.; Zhu, Y.-M.; Tang, L.; Zhang, X.-W.; et al. Exome sequencing identifies somatic mutations of DNA methyltransferase gene DNMT3A in acute monocytic leukemia. Nat. Genet. 2011, 43, 309-315. [CrossRef]

41. Makishima, H.; Yoshida, K.; Nguyen, N.; Przychodzen, B.; Sanada, M.; Okuno, Y.; Ng, K.P.; Gudmundsson, K.O.; Vishwakarma, B.A.; Jerez, A.; et al. Somatic SETBP1 mutations in myeloid malignancies. Nat. Genet. 2013, 45, 942-946. [CrossRef]

42. Coccaro, N.; Tota, G.; Zagaria, A.; Anelli, L.; Specchia, G.; Albano, F. SETBP1 dysregulation in congenital disorders and myeloid neoplasms. Oncotarget 2017, 8, 51920-51935. [CrossRef] [PubMed]

43. Patel, J.L.; Schumacher, J.A.; Frizzell, K.; Sorrells, S.; Shen, W.; Clayton, A.; Jattani, R.; Kelley, T.W. Coexisting and cooperating mutations in NPM1-mutated acute myeloid leukemia. Leuk. Res. 2017, 56, 7-12. [CrossRef] [PubMed] 